\title{
A Comprehensive Review: Molecular and Genetic Background of Indirect Inguinal Hernias
}

\author{
Salih Somuncu ${ }^{a}$ Özge Sezin Somuncu ${ }^{b}$ \\ ${ }^{a}$ Department of Pediatric Surgery, Bezmialem Vakıf University Faculty of Medicine, İstanbul, Turkey; \\ ${ }^{b}$ Department of Pathology, Stony Brook Medicine, New York, NY, USA
}

\section{Keywords}

Indirect inguinal hernia - Epithelial-mesenchymal transition · Genetics

\begin{abstract}
Background: The occurrence of indirect inguinal hernias $(\mathrm{IIH})$ is 5 times more prevalent than that of direct inguinal hernias $(\mathrm{IH})$ and it is 7 times more common in males, owing to the attendance of the processus vaginalis (PV) throughout testicular descent. Summary: In children, the immense mainstream of $\mathrm{IH}$ is indirect. The progress of $\mathrm{IIH}$ development in children is instigated with a patent PV, which is mostly treated by simple herniorrhaphy. Syndromes of the collagen, microfibril, elastin, and glycosaminoglycan constituents of the extracellular matrix may attend to the development of $\mathrm{IH}$. Our recent research showed that the lack of epithelial-mesenchymal transition (EMT) in children contributes to the development of $\mathrm{IH}$, while the scenario is defined as the opposite in adults. However, there is still a lack of knowledge on all of the genetic and molecular causes of the disease. Key Messages: Here we aimed to review the published genetic background of $\mathrm{IH}$, the deficiencies of connective tissue causing the disease, recently defined molecular pathways involved including EMT, and possible recurrence reasons. This comprehensive study can deliver an analytic outline aiding to define patients with $\mathrm{IH}$ combined with fundamental genetic diseases. 02021 The Author(s)

Published by S. Karger AG, Basel
\end{abstract}

\section{Introduction}

Inguinal hernia $(\mathrm{IH})$ reparation is the most prevalent medical practice implemented in childhood, with a total occurrence range of $0.8-4.4 \%[1,2]$. In most cases, the hernia is indirect and mainly caused by late closure of the processus vaginalis (PV) in children. Generally, peritoneum introverts to the PV across the internal ring, which is formed by the twelfth week of gestation, and then turns into a tract where the intra-abdominal testis descends to the scrotum. Subsequent to an effective testicular descent, the PV typically obliterates over the descended testis [2].

The mechanism behind the closure of the PV remains obscure. Most of the time, reappearance of a pediatric $\mathrm{IH}$ depends on the imperfect obliteration of the PV through surgical restoration. Additionally, the probability of atypical connective tissue residing inside the inguinal canal (IC) has been thought to be the other reason for IH for many years $[3,4]$.

While hernia reappearance in children is less usual than in adults, for whom relapse incidences of $5-10 \%$ are documented, it remains as a medical difficulty. The occurrence of hernia reappearance in children is stated to be between 0.8 and $3.8 \%$; nevertheless, the exact frequency of relapse is unidentified and can be more than what the studies indicate [5].

The former studies propose that the following subsequent aspects may prompt IH reappearance: insufficiency to ligate the sac high enough at the internal ring, an outsized inner inguinal ring, damage to the base of the IC from surgical disturbance, fault in obstructing the internal inguinal ring in female patients, genetic impotence of 
the tissues in individuals having connective tissue syndromes, deprived sustenance, prematurity, development defect complaints related to amplified intra-abdominal pressure (ventriculoperitoneal shunt, ascites, pulmonary circumstances with urethral valves, chronic coughing, bladder exstrophy, and lifting heavy weights), restrained hernia necessitating an emergency procedure, postoperative wound infection and hematoma, and delayed orchiopexy in infants with concomitant undescended testes. Identification of the influences of moderate surgical techniques, alterations in the surgical method built on discerning categorization of patients at great risk of repetition, and initial optional restoration before restraining may be beneficial in dropping the frequency of relapse [6].

Indirect IH (IIH) has been associated with other clinical syndromes, such as Marfan syndrome (MFS), LoeysDietz syndrome (LDS), and Ehlers-Danlos syndrome [7]. Genetic defects in constituents of IC, involving collagen, elastic fiber, and ECM, in addition to abdominal wall muscles, can trigger IIH expansion [8]. Coran and Eraklis [9] reported a $56 \%$ relapse frequency subsequent to elevated ligation of the indirect hernia sac in infants with Hurler-Hunter syndrome [10]. McEntyre and Raffensperger published a paper recommending infants and children with Ehlers-Danlos syndrome undergo a formal herniorrhaphy parallel to ones implemented in adult patients [11]. The related interpretations suggest that foregoing operative trauma can change the standing of the tissues on the ground of the IC in the infant and might prompt the patient to an abnormal form of repeated hernia $[12]$.

\section{Connective Tissue-Related Molecular Mechanisms for IH}

The IC contains tissue formed by collagen, elastic fibers involving elastin and microfibrils, and the glycosaminoglycans of the ECM. Genetic defects of every single one of these fundamental constituents of a healthy connective tissue structure may cause an enhanced frequency of $\mathrm{IH}[2]$.

\section{Collagen}

Collagen is the ending substance of action inside the fibroblast. Type I and type III collagens are the 2 central forms among 29 that have been linked to wound healing and hernia development. Initially, the fibroblast creates procollagen, a long triple-helix molecule covering 2 amino acids, i.e., lysine and proline. With the presence of oxygen, $\mathrm{Cu}$, and $\mathrm{Fe}^{+2}$, hydroxylation supersedes with transformation to hydroxyproline and hydroxylysine that are then exported as extracellular tropocollagen. Robust con- nections grow between analogous filaments of tropocollagen and create collagen fibrils and fibers through wound margins. Type I collagen is central in the advanced sturdier wound, whereas type III collagen, is nonpolymeric and soluble and acts through the initial phases of wound recovery [13]. Type III collagen is not an adequate barrier and can trigger herniation and genitourinary prolapse [14]. Reduced hydroxylation has been stated with $\mathrm{DIH}$ versus IIH. The proportion of type I/III depends on the firmness of the collagen strand and the fibril width. A reduction of type I or an upsurge in type III has been associated with herniation, smoking, and hereditary instigates [4].

Particular scientific groups, though not decisive, have attempted to measure structural modifications of collagen in hernias. Rodrigues Junior et al. [8] and Quintas et al. [15] indicated organizational and quantifiable agelinked alterations in the transversalis fascia (TF) elastic fibers. These outcomes designated openly that there is a structural correlation to the forfeiture of tensible capacitance and springiness of the TF with aging, and this could explain the excessive frequency of $\mathrm{IH}$ in people older than 50 years $[8,15,16]$.

Rodrigues Junior et al. [8] established that the collagen substance per milligram of TF was less in DIH than in IIH patients. Wagh et al. [17] additionally revealed a meaningfully reduced collagen intensity in the rectus sheaths of hernia patients. Pans et al. [18] showed an augmented collagen substance in the TF from IIH and a noteworthy upsurge in collagen consistent with unripe collagen in the TF from DIH. This shift might be coming from an improved collagen revolution frequency or enhanced disintegration of collagen by matrix metalloproteinases (MMP) [18]. Bellón et al. [19] indicated an amplified level of MMP2 in the TF in DIH in proportion to IIH.

\section{Microfibrils}

Elastic fibers are vigorous extracellular fibers that deliver springiness to tissues. Every elastic fiber contains an elastin core and a microfibril cover. Microfibrils are glycoproteins vital to the production and structural constancy of elastic fibers. Fifteen different proteins have been revealed to be inclusive in microfibril production; nevertheless the glycoprotein fibrillin-1 (FBN1) has a significant function. The initial step of elastic fiber construction is microfibril assembly, where the fibrillin microfibril bundle is shaped via the connection of elastin aggregates [20]. In the prenatal and in early postnatal stages, microfibrils form a cover across a main cross-linked core of elastin. These recently shaped elastic fibers deposit in the skin, elastic arteries, aorta, ligaments, and additional elastic connective tissues around the body [21].

The most communal syndrome of the microfibril is MFS, which is instigated by modifications in the FBN1 
Fig. 1. The IC covers tissues made by collagen, elastin, and microfibrils and the ECM. Genetic faults of these elements or chromosomal abnormalities may cause a heightened incidence of herniation. FBN, fibrillin-1. This image was created using the certified illustration software BioRender.

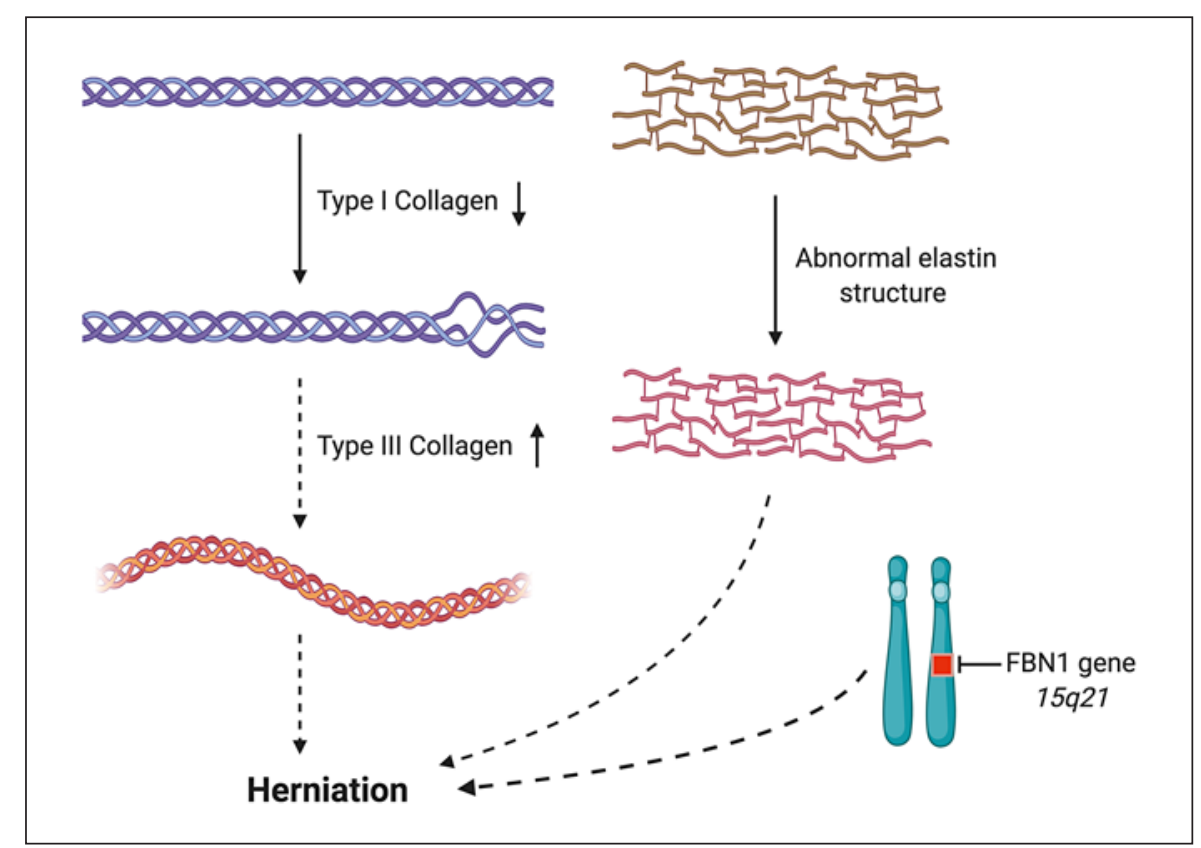

gene located at chromosome 15 (15q21.1), causing irregular FBN1 synthesis, discharge, or usage. While recurring $\mathrm{IH}$ is comprised in the indicative norms for MFS, there are also a few studies mentioning the occurrence of $\mathrm{IH}$ in MFS [22]. Finkbohner et al. [23] stated a prevalence of $34 \%$ of IH in 192 MFS patients. The commonness of IH in MFS patients with confirmed irregularities in fibrillin occupation, with or without a fibrillin mutation, was stated as $42 \%$ in another study [24].

LDS is an autosomal dominant disorder with key displays in the heart and skeletal system. It was primarily defined as resembling MFS. LDS is instigated via alterations in the transforming growth factor (TGF) receptor 1 and 2 genes [25]. Microfibrils control TGF- $\beta$, and extreme TGF- $\beta$ stimulation is heavily associated with fibrillinopathies. The precise microfibrillar aberration in LDS is unidentified; however, a molecular analysis for this disorder is obtainable [26].

Research has also been conducted to define the mutations in the elastin gene in patients with no chromosomal syndromes. Rodrigues et al. [27] proved the assumption that the ELNf (elastin isoform $\mathrm{f}$ precursor) gene exon 20 g28197A > G missense mutation triggers the construction of irregular elastic fibers and the forfeiture of fascia transversalis utility and therefore is involved in the genesis of IH. Rodrigues Junior et al. [8] showed elevated quantities of elaunin and oxytalan elastic fibers in TF from DIH patients compared to IIH patients in another study. The advanced volumes of elastic fibers were shown to have no effect on promotion improved tissue flexibility, since these elastic fibers in TF from DIH patients exhibited structural alterations. They indicated that elastic fibers converted to twisted, dense, and disintegrated versions and mislaid their unique utility. Briefly, the TF from DIH patients had worse endurance and springiness compared to the TF from IIH patients [8]. The connective tissue abnormalities that cause herniation are illustrated in Figure 1.

\section{Gene Expression Patterns in IIH}

\section{Sirtuins}

Sirtuins are very preserved NAD-dependent class III deacetylases. The sirtuin family consists of 7 members, i.e., SIRT1 to SIRT7, in humans [28]. SIRT1 controls an extensive variation of cellular roles including mitochondrial autophagy, circadian rhythms, biogenesis, stress resistance, programmed cell death, glucose, and lipid metabolism. The SIRT1 has been widely investigated and is involved in cancer, diabetes, cardiovascular diseases, inflammation, obesity, and neurodegeneration [29]. Commonly, the SIRT1 gene is highly expressed in human skeletal muscles. SIRT1 has been indicated to control the differentiation of skeletal muscle cells [30]. It also stimulates the proliferation of human fibroblasts [31]. In one study, researchers heritably and physiologically examined the SIRT1 gene promoter in IIH patients and controls. A small number of DNA sequence variants (DSV) and single-nucleotide polymorphisms (SNP) have been defined in IIH patients that meaningfully changed SIRT1 gene promoter actions in vitro. The DSV might have altered the transcriptional actions of the SIRT1 gene promoter and altered SIRT1 levels, contributing to IIH progression 
as a risk cause. Comprehending the genetic and fundamental background can aid surgeons in competently treating patients with primary and persistent IH [32].

\section{GATA Factor 6}

GATA factor 6 (GATA6) is a member of the GATA transcription factor family comprising a vastly preserved DNA-binding domain. Throughout embryonic growth, GATA factors control cellular differentiation, propagation, and subsistence [33]. GATA6 is mostly abundant in the lung, heart, and gastrointestinal tract in human embryos. Instead, GATA6 is generally expressed in mesodermal and endodermal tissues $[34,35]$. Alterations in the GATA6 have been linked to congenital heart disorders, atrial fibrillation, high blood glucose, and pancreatic agenesis [36-38]. Additionally, the latest research has associated GATA6 gene alterations with genetic diaphragmatic hernia [39]. In one study, researchers examined the GATA6 gene promoter in IIH patients and controls. Theyfound 2 heterozygous DSV,i.e., g.22168361C $>$ A and g.22169106C $>\mathrm{T}$, in 2 IIH patients, but not in any of the controls. These DSV meaningfully decreased the GATA6 gene promoter actions in cultured human fibroblasts. Furthermore, 3 heterozygous DSV were only discovered in 3 controls. Five DSV covering 4 SNP and 1 novel variant were uncovered in both IIH patients and controls with parallel incidences. Consequently, it was proved that the DSV inside the GATA6 gene promoter contributed to IIH progression as a risk cause by fluctuating GATA6 expressions [40].

\section{Matrix Metalloproteinases}

MMPs are from the zinc-dependent endopeptidase protein family with diverse practical biological properties covering cell expansion and programmed cell death, contrasting consequences on angiogenesis, and changes in cellular movement and the immune system. MMPs take part in ECM metabolism as mediators of tissue makeover and overhaul [41].

The distorted percentage of the collagen subtypes may be caused by either an altered production or unstable deterioration. Cleavage is controlled by the action of the MMPs. MMP 1 and MMP13 are the major matrix enzymes splitting fibrillar type I, II, and III collagens. They have been shown to carry a pathological function in disproportionate breakdown of particular connective tissue constituents, osteoarthritis, atherosclerosis, tumor cell spreading, and metastasis [42]. Especially changes in MMP1 and MMP13 protein expressions have been linked to different proportions of type I to III collagen [43]. Nonetheless, as initially publicized in studies by Bellón et al. [16], cultured fibroblasts in the fascia transversalis of $\mathrm{IH}$ patients displayed no alterations in MMP1 expression, while they then revealed MMP-2 overexpression in the patients.
Smigielski et al. [44] indicated elevated levels of serum MMP2 in IIH, DIH, and incisional hernias. Meanwhile, Jain et al. [45] conducted a study including 30 patients and 30 controls and the outcomes were comparable to those in the study of Smigielski et al. [44]. Smigielski et al. [46] then evaluated MMP2 and TIMP2 (tissue inhibitors of metalloproteinase-2) levels in $\mathrm{DIH}, \mathrm{IIH}$, and recurrent hernia patients. They found that both factors were enhanced in hernia patients instead of the control group [46]. Another study with greater numbers of experimental subjects was completed by Antoniou et al. [47]. They examined tissue MMP2, MMP9, and TIMP1 and TIMP2 expressions of $91 \mathrm{IH}$ and 35 control patients. MMP2 and MMP9 expressions were increased while TIMP1 and TIMP2 were decreased in the IH group compared to the control group [47]. Bellón et al. [16] evaluated the relative expressions of both MMP2 and TIMP2 in skin biopsies of $\mathrm{DIH}, \mathrm{IIH}$, and control groups. MMP2 expression was found very abundant in the IH groups while TIMP2 was very abundant in the control groups. The results indicated that IH might develop because of a native contemplation of systemic diseases.

\section{T-Box Transcription Factor 2}

T-box transcription factor 2 (TBX2) is a transcription factor with important responsibilities in embryonic expansion. The TBX2 gene is extensively expressed in humans. It has been associated with the morphogenesis of numerous tissues and organs such as the lungs, kidneys, mammary glands, limbs, the heart, testes, and cranial tissues. Parallel expression profiles of the TBX2 gene have been detected in animal models, suggesting that Tbx 2 is also a key controller that works as a dose-responsive repressor. Tbx 2 expression is found in somites that mature into vertebrae and muscles, whereas it also is expressed in abdominal tissues. It is hypothesized that altered TBX2 expressions triggered by the DSV inside the TBX2 gene regulatory sections can lead to human disorders [48].

Zhang et al. [48] identified 6 DSV inside of the TBX2 gene promoter. They showed that one IIH patient had a heterozygous DSV (g.59476307G $>$ C). They also detected 4DSV,i.e., g.59476316C $>\mathrm{A}(\mathrm{rs} 73991913)$, g.59476415T $>\mathrm{C}$ (rs1476781), g.59476510G $>\mathrm{C}$ (rs4455026), and g.59476892C $>$ T (rs2286524), all of which were SNP and presented in both IIH patients and controls with parallel rates. The results indicated that DSV might be involved in IIH development as an occasional reason through shifting of the TBX2 level.

\section{TBX3}

Through embryonic development of the mouse, the $\mathrm{Tbx} 3$ is broadly expressed in diverse tissues and organs similar to TBX2 involving the mammary glands, lungs, the heart, limbs, the nervous system, the genital ridge and 
the thoracic and abdominal body wall. Human TBX3 gene expression profiles are similar to those of mice while also being expressed in connective tissues. Furthermore, TBX3 has been covered in preserving the undifferentiated state of ESC and refining the superiority of iPSC [49]. Heterozygous alterations in the TBX3 gene instigate ulnar-mammary syndrome, which is defined by upperlimb deformities distressing the ulnar ray, mammary gland hypoplasia, and apocrine and genital deficiencies. As described before, $\mathrm{IH}$ has been detected in a minor percentage of ulnar-mammary syndrome patients [50].

Since TBX3 activity is highly dose dependent, Zhao et al. [49] studied a TBX3 gene promoter in IIH patients and ethnically complemented controls. They identified a heterozygous deletion variant (g.4820_4821del) in $1 \mathrm{IIH} \mathrm{pa-}$ tient but in none of the controls. Accordingly, the variant meaningfully reduced TBX3 gene promoter activity, prone to generating a binding site for sex-determining region Y (SRY), a mobility group transcription factor. The research group also found 1 heterozygous insertion variant (g.3913_3914ins) only in 1 control, which did not distress TBX3 gene promoter actions. Generally, TBX3 gene variants might contribute to IIH as an infrequent risk factor via a decrease in TBX3 intensities [49].

\section{Genome-Wide Association Studies and Whole Exome Sequencing in IIH}

Limited information has been identified regarding the genes that play a role in the pathophysiology of IH. Jorgenson et al. [51] performed the first large-scale genomewide association study of surgically confirmed IH. They used the data of patients in the Genetic Epidemiology Research in Adult Health and Aging (GERA) cohort, nested in the Kaiser Permanente Integrated Health Plan in Northern California (KPNC). They projected the point occurrence of surgically established IH between non-Hispanic white KPNC participants older than 50 years, which was $9.2 \%$ in men and $0.3 \%$ in women. With the aid of both point and lifetime incidence assessments, the 4 top SNPs (on gene EFEMP1, ADAMTS6, EBF2, and WT1) enlightened $1.0-1.4 \%$ of the distinction in the risk of IH in men and $1.3-2.8 \%$ in women in their detection sample. The narrow-sense heritability described through shared SNP was between 13.2 and $18.3 \%$ in men and between 20.8 and $25.5 \%$ in women, signifying that further IH predisposition loci are yet to be determined [51].

They also examined the $4 \mathrm{IH}$ probable SNPs in GERA participants with DIH and IIH distinctly to define whether any of them predisposed subjects to a precise subtype of IH. The OR detected for DIH were marginally stronger for 3 of the 4 top SNP in men versus IIH. They detected fewer subjects with IH among women; only rs2009262
(EFEMP1 gene SNP) and rs3809060 (WT1 gene SNP) were associated with DIH or IIH and both exhibited greater effects in IIH compared to DIH. In men, the 4 top SNP have been defined as the most intensely connected SNP with IIH. However, for 3 of the 4 loci, different SNP in the sequence have been linked to DIH, particularly rs11899888 (instead of rs2009262) in EFEMP1, rs12520760 (instead of rs370763) in ADAMTS6, and rs10746560 (instead of rs6991952) in EBF2 [51].

The potential inheritance pattern of IH is still unclear, and not many genetic findings have been stated for humans that might be considered at the whole-genome level. A recent study performed by Mihailov et al. [52] showed the heterozygous missense mutation c.88880A $>C$ (p.Lys29627Thr) in the TTN gene encoding titin, which cosegregated with $\mathrm{IH}$ in an Estonian multiplex family through whole-exome sequencing. They stated that this missense variant in the A-band of TTN is the clearest potential mutation for autosomal dominant $\mathrm{IH}$ with partial penetrance [52].

\section{Epithelial-Mesenchymal Transition in IIH}

Epithelial-mesenchymal transition (EMT) defines a fast and regularly reversible conversion of the cellular phenotype. It was initially stated in the framework of the cell transformation that has been utilized in a variety of actions, involving mesoderm and neural crest development [53]. Through EMT, epithelial cells mislay their distinctive cell-cell adhesion assemblies, alter polarity, control the incorporation of their cytoskeletal meshwork, shift expression from keratin to vimentin type transitional filaments, and convert into remote, motile cells that are defiant to cell death [54]. Structural modifications of obliterated PV are the counterpart of EMT. Cells residing in the PV express cytokeratins and establish diversity of epithelial cells [55]. This implies that EMT may be the cause of cells granting the capacity to attack the ECM. Oncostatins have been reported to prompt EMT in tubular epithelial cells through stimulation of the STAT pathway, signifying that STAT can be vital for cytokine- and growth factor-facilitated reactions controlling EMT in cancer and fibrogenesis [56].

Our recent report on the investigation of the related topic indicated significant results. In children with $\mathrm{IIH}$ keratin expression was detected higher than the controls, while keratin expression was significantly lower in adult IIH than adult controls. Keratin 15, keratin 1, and Filaggrin 2 expressions all correlated as they are participants of connected pathways, while signal transducer and activator of transcription 3 (STAT3) expressions were found opposite to Keratin and Filaggrin, proposing that adult cells shifted to the mesenchymal state from 
Table 1. Summary of our findings in adult vs. pediatric IH indicating differences of EMT-related genes

\begin{tabular}{|c|c|c|c|c|c|}
\hline Target genes & $\begin{array}{l}\text { Experimental } \\
\text { groups }\end{array}$ & $\begin{array}{l}\text { Relative mRNA } \\
\text { expression }\end{array}$ & Results & Outcome & Reference \\
\hline $\begin{array}{l}\text { KRT15 } \\
\text { (keratin 15) }\end{array}$ & $\begin{array}{l}\text { Adult peritoneum } \\
\text { Adult IIH } \\
\text { Pediatric peritoneum } \\
\text { Pediatric IIH }\end{array}$ & $\begin{array}{l}0.056 \pm 0.014 \\
0.194 \pm 0.013\end{array}$ & $\begin{array}{l}\text { Higher expression of KRT15 in } \\
\text { pediatric IIH vs. controls } \\
\text { Lower expression of KRT15 in adult } \\
\text { IIH vs. controls }\end{array}$ & $\begin{array}{l}\text { Adult IIH } \\
\text { Mesenchymal state } \uparrow \\
\text { Pediatric IIH } \\
\text { Epithelial state } \uparrow\end{array}$ & 59 \\
\hline $\begin{array}{l}\text { KRT1 } \\
\text { (keratin 1) }\end{array}$ & $\begin{array}{l}\text { Adult peritoneum } \\
\text { Adult IIH } \\
\text { Pediatric peritoneum } \\
\text { Pediatric IIH }\end{array}$ & $\begin{array}{l}0.164 \pm 0.013 \\
0.240 \pm 0.014\end{array}$ & $\begin{array}{l}\text { Higher expression of KRT1 in } \\
\text { pediatric IIH vs. controls } \\
\text { Lower expression of KRT1 in adult } \\
\text { IIH vs. controls }\end{array}$ & $\begin{array}{l}\text { Adult IIH } \\
\text { Mesenchymal state } \uparrow \\
\text { Pediatric IIH } \\
\text { Epithelial state } \uparrow\end{array}$ & 59 \\
\hline $\begin{array}{l}\text { FLG2 } \\
\text { (filaggrin 2) }\end{array}$ & $\begin{array}{l}\text { Adult peritoneum } \\
\text { Adult IIH } \\
\text { Pediatric peritoneum } \\
\text { Pediatric IIH }\end{array}$ & $\begin{array}{l}0.068 \pm 0.011 \\
0.190 \pm 0.013\end{array}$ & $\begin{array}{l}\text { Higher expression of FLG2 in } \\
\text { pediatric IIH vs. controls } \\
\text { Lower expression of FLG2 in adult } \\
\text { IIH vs. controls }\end{array}$ & $\begin{array}{l}\text { Adult IIH } \\
\text { Mesenchymal state } \uparrow \\
\text { Pediatric IIH } \\
\text { Epithelial state } \uparrow\end{array}$ & 59 \\
\hline $\begin{array}{l}\text { STAT3 } \\
\text { (signal transducer } \\
\text { and activator of } \\
\text { transcription 3) }\end{array}$ & $\begin{array}{l}\text { Adult peritoneum } \\
\text { Adult IIH } \\
\text { Pediatric peritoneum } \\
\text { Pediatric IIH }\end{array}$ & $\begin{array}{l}0.364 \pm 0.0061 \\
0.364 \pm 0.0063\end{array}$ & $\begin{array}{l}\text { Same expression of STAT3 in } \\
\text { pediatric IIH and controls } \\
\text { Higher expression of STAT3 in adult } \\
\text { IIH vs. controls }\end{array}$ & $\begin{array}{l}\text { Adult IIH } \\
\text { Mesenchymal state } \uparrow\end{array}$ & 59 \\
\hline
\end{tabular}

the epithelial state. Adult IIH samples converted to the mesenchymal state while child IIH samples displayed an absence of transition. In other words, child IH cells maintained their epithelial stage and did not enter the mesenchymal phase. Subsequent to this study, EMT can be thought as a factor of IIH development in adults while the arrested EMT might be the factor of child IIH [57] (Table 1). The genes effecting IIH development and EMT effects are shown in Figure 2 with respect to the reference studies.

Overall, abnormal deviations of EMT-related genes influence the development of IIH. Thus, the report on both genetic and epigenetic control of EMT in patients with primary IH may help to understand the pathogenesis and bring new therapeutic methods for this disease [57].

\section{Discussion}

An IH grows when the PV decays to obliteration in late gestation, allowing interactions between the abdominal cavity and the IC to endure. Abdominal substances can later herniate into the IC. The predominance of hernias in children are indirect, with substances expanded throughout the internal inguinal ring into the IC [58].
There is still a lack of information on how IH carry the recurrence possibility in adults but not very often in children. Meanwhile, some genetic malformations cause the development of IH and may contribute to the relapse possibility. How child indirect IH develops through different molecular paths compared to other hernia types is not yet fully understood.

Now, it is very clear that connective tissue deficiencies attend to the progression of IH. For instance, as a result of a fundamental faulty collagen metabolism, the degree of mash overlap can create the risk of a recurrence emerging at the mesh border. Therefore, the background information of genetic abnormalities or metabolism deficiencies may support the surgeon's decision on the surgical method [59].

The congenital perspective of child IIH is intended to be under intense examination by our group soon. Though EMT upregulation was initially established in adult IIH and not in child IIH, a superior understanding of EMT genes in diverse populaces are now being engaged to comprehend the pathophysiology and genetic context of the disorder. This may be beneficial for selection of the patients at risk who would possibly benefit from surgical reparation with prosthetic material [57].

As indicated by many previous studies, the basic mechanism in the formation of IH develops through oblitera- 


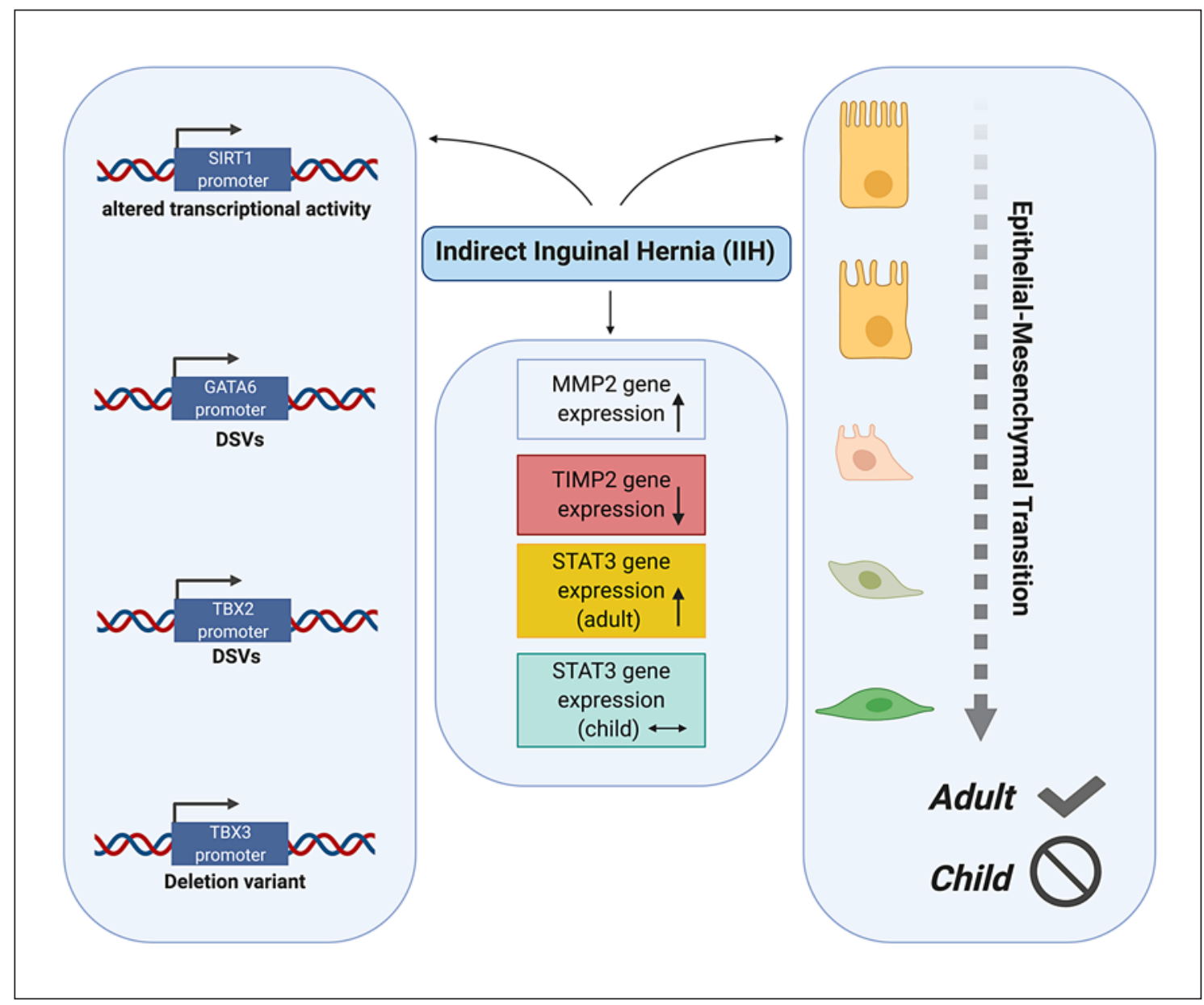

Fig. 2. IIH development may be triggered by altered transcriptional activities of the SIRT1 promoter, DSV of GATA6, and TBX2 promoters and deletion variants of the TBX3 promoter $[40,48,51]$. Relative mRNA expression differences in MMP2, TIMP2, and STAT3 $[46,56]$ genes are also involved in disease progression. Child IIH cells were found not to be entering EMT recently [56]. GATA, GATA binding protein 6; TIMP, tissue inhibitor of metallopeptidases; STAT3, signal transducer and activator of transcription 3. This image was created using the certified illustration software BioRender.

tion of the PV $[2,60,61]$. Although there is not much information in the literature [62], we speculate that the obliteration defect of $\mathrm{PV}$ in $\mathrm{IH}$, along with undescended testicles in infancy, is similar to IH seen at an early age in girls with a sliding ovary, in line with the observations of many cases and operations. We also speculate that obliteration of the PV occurs with a different deficiency in $\mathrm{IH}$ seen in girls and boys at advanced pediatric ages. Therefore, in one of our ongoing studies, we are working on the EMT background by taking PV samples of IH with undescended testicles during infancy, sliding IH in infant girls, and $\mathrm{IH}$ seen at advanced pediatric ages. Thus, we aim to explain the molecular differences of these studies in 2 different pathologies. When the molecular mechanism in the obliteration of PV is solved in the future, especially in infancy cases, the treatment of the disease will be found with molecular therapies that can be developed without the need for surgery.

\section{Conclusion}

$\mathrm{IH}$ is a disease that is formed by many multifactorial reasons such as genetic factors, differences in ECM elements, and EMT deficiency. In this study, we discussed these factors one by one and shared the latest developments in the literature. This review supports the idea of taking molecular background studies into consideration since the future diagnostic approaches and treatments for $\mathrm{IH}$ are changing shape. Our group aims to fully describe the molecular mechanism of child and adult IH in the future. Here we demonstrated the multifactorial background of IH by focusing on the molecular pathways that are involved. 


\section{Acknowledgement}

We would like to thank the Bezmialem University Faculty of Medicine and Adam Naqvi from the Department of Pathology at Stony Brook Medicine for their support.

\section{Conflict of Interest Statement}

The authors declared that no competing interests exist.

\section{Funding Sources}

The authors received no specific funding for this work.

\section{Author Contributions}

All of the authors contributed to the preparation and editing of this paper.

\section{References}

1 McCormack K, Scott NW, Go PM, Ross S, Grant AM; EU Hernia Trialists Collaboration. Laparoscopic techniques versus open techniques for inguinal hernia repair. CochraneDatabaseSystRev.2003;(1):CD001785.

2 Barnett C, Langer JC, Hinek A, Bradley TJ, Chitayat D. Looking past the lump: genetic aspects of inguinal hernia in children. J Pediatr Surg. 2009 Jul;44(7):1423-31.

3 Grosfeld JL, Minnick K, Shedd F, West KW, Rescorla FJ, Vane DW. Inguinal hernia in children: factors affecting recurrence in 62 cases. J Pediatr Surg. 1991 Mar;26(3):283-7.

4 Henriksen NA, Yadete DH, Sorensen LT, Agren MS, Jorgensen LN. Connective tissue alteration in abdominal wall hernia. Br J Surg. 2011 Feb;98(2):210-9.

5 Canonico S. Inguinal hernia. BoD-Books on Demand; 2014.

6 Rafiei MH, Jazini A. Is the ligation of hernial sac necessary in herniotomy for children? A randomized controlled trial of evaluating surgical complications and duration. Adv Biomed Res. 2015 May;4(1):97.

7 Meester JA, Verstraeten A, Schepers D, Alaerts M, Van Laer L, Loeys BL. Differences in manifestations of Marfan syndrome, Ehlers-Danlos syndrome, and Loeys-Dietz syndrome. Ann Cardiothorac Surg. 2017 Nov;6(6):582-94.

8 Rodrigues Junior AJ, Rodrigues CJ, da Cunha AC, Jin Y. Quantitative analysis of collagen and elastic fibers in the transversalis fascia in direct and indirect inguinal hernia. Rev Hosp Clin Fac Med Sao Paulo. 2002 Nov-Dec;57(6): 265-70.

9 Coran AG, Eraklis AJ. Inguinal hernia in the Hurler-Hunter syndrome. Surgery. 1967 Feb; 61(2):302-4.

10 Steinau G, Treutner KH, Feeken G, Schumpelick V. Recurrent inguinal hernias in infants and children. World J Surg. 1995 MarApr;19(2):303-6.

11 McEntyre RL, Raffensperger JG. Surgical complications of Ehlers-Danlos syndrome in children. J Pediatr Surg. 1977 Aug;12(4):5315.

12 Amid P, Lichtenstein I. Long-term result and current status of the Lichtenstein open tension-free hernioplasty. Hernia. 1998;2(2):8994.

13 Xue M, Jackson CJ. Extracellular Matrix Reorganization During Wound Healing and Its Impact on Abnormal Scarring. Adv Wound Care (New Rochelle). 2015 Mar;4(3):119-36.
14 Friedman DW, Boyd CD, Norton P, Greco RS, Boyarsky AH, Mackenzie JW, et al. Increases in type III collagen gene expression and protein synthesis in patients with inguinal hernias. Ann Surg. 1993 Dec;218(6):75460.

15 Quintas ML, Rodrigues CJ, Yoo JH, Rodrigues Junior AJ. Age related changes in the elastic fiber system of the interfoveolar ligament. Rev Hosp Clin Fac Med Sao Paulo. 2000 May-Jun;55(3):83-6.

16 Bellón JM, Bajo A, Ga-Honduvilla N, Gimeno MJ, Pascual G, Guerrero A, et al. Fibroblasts from the transversalis fascia of young patients with direct inguinal hernias show constitutive MMP-2 overexpression. Ann Surg. 2001 Feb; 233(2):287-91.

17 Wagh PV, Leverich AP, Sun CN, White HJ, Read RC. Direct inguinal herniation in men: a disease of collagen. J Surg Res. 1974 Dec; 17(6):425-33

18 Pans A, Albert A, Lapière CM, Nusgens B. Biochemical study of collagen in adult groin hernias. J Surg Res. 2001 Feb;95(2):107-13.

19 Bellón JM, Buján J, Honduvilla NG, Jurado F, Gimeno MJ, Turnay J, et al. Study of biochemical substrate and role of metalloproteinases in fascia transversalis from hernial processes. Eur J Clin Invest. 1997 Jun;27(6):510-6.

20 Kielty CM, Sherratt MJ, Shuttleworth CA. Elastic fibres. J Cell Sci. 2002 Jul;115(Pt 14): 2817-28.

21 Kristensen J, Karsdal M. Elastin. Biochemis try of Collagens, Laminins and Elastin. Elsevier; 2016. pp. 197-201.

22 Judge D, Dietz HC. Marfan's syndrome. Lancet. $1965 ; 1976$

23 Finkbohner R, Johnston D, Crawford ES, Coselli J, Milewicz DM. Marfan syndrome. Long-term survival and complications after aortic aneurysm repair. Circulation. 1995 Feb;91(3):728-33.

24 Robinson PN, Arteaga-Solis E, Baldock C, Collod-Béroud G, Booms P, De Paepe A, et al. The molecular genetics of Marfan syndrome and related disorders. J Med Genet. 2006 Oct; 43(10):769-87.

25 Singh KK, Rommel K, Mishra A, Karck M, Haverich A, Schmidtke J, et al. TGFBR1 and TGFBR2 mutations in patients with features of Marfan syndrome and Loeys-Dietz syndrome. Hum Mutat. 2006 Aug;27(8):770-7.

26 Chaudhry SS, Cain SA, Morgan A, Dallas SL, Shuttleworth CA, Kielty CM. Fibrillin-1 regulates the bioavailability of TGFbeta1. J Cell Biol. 2007 Jan;176(3):355-67.
27 Rodrigues CJ, Yoo JH, Rodrigues AJ Jr. Elastin (ELN) gene point mutation in patients with inguinal hernia. Genet Mol Biol. 2006; 29(1):45-6.

28 North BJ, Verdin E. Sirtuins: Sir2-related NAD-dependent protein deacetylases. Genome Biol. 2004;5(5):224.

29 Wu Y, Meng X, Huang C, Li J. Emerging role of silent information regulator 1 (SIRT1) in hepatocellular carcinoma: a potential therapeutic target. Tumour Biol. 2015 Jun;36(6): 4063-74.

30 Pardo PS, Boriek AM. The physiological roles of Sirt1 in skeletal muscle. Aging (Albany NY). 2011 Apr;3(4):430-7.

31 Huang J, Gan Q, Han L, Li J, Zhang H, Sun Y, et al. SIRT1 overexpression antagonizes cellular senescence with activated ERK/S6k1 signaling in human diploid fibroblasts. PLoS One. 2008 Mar;3(3):e1710.

32 Han Q, Zhang Y, Li W, Fan H, Xing Q, Pang $S$, et al. Functional sequence variants within the SIRT1 gene promoter in indirect inguinal hernia. Gene. 2014 Aug;546(1):1-5.

33 Burch JB. Regulation of GATA gene expression during vertebrate development. Semin Cell Dev Biol. 2005 Feb;16(1):71-81.

34 Huggon IC, Davies A, Gove C, Moscoso G, Moniz C, Foss Y, et al. Molecular cloning of human GATA-6 DNA binding protein: high levels of expression in heart and gut. Biochim Biophys Acta. 1997 Aug;1353(2):98-102.

35 Jimenez P, Saner K, Mayhew B, Rainey WE. GATA-6 is expressed in the human adrenal and regulates transcription of genes required for adrenal androgen biosynthesis. Endocrinology. 2003 Oct;144(10):4285-8.

36 Kodo K, Nishizawa T, Furutani M, Arai S, Yamamura E, Joo K, et al. GATA6 mutations cause human cardiac outflow tract defects by disrupting semaphorin-plexin signaling. Proc Natl Acad Sci USA. 2009 Aug;106(33):139338.

37 Allen HL, Flanagan SE, Shaw-Smith C, De Franco E, Akerman I, Caswell R, et al.; International Pancreatic Agenesis Consortium. GATA6 haploinsufficiency causes pancreatic agenesis in humans. Nat Genet. 2011 Dec; 44(1):20-2.

38 De Franco E, Shaw-Smith C, Flanagan SE Shepherd MH, Hattersley AT, Ellard S; International NDM Consortium. GATA6 mutations cause a broad phenotypic spectrum of diabetes from pancreatic agenesis to adultonset diabetes without exocrine insufficiency. Diabetes. 2013 Mar;62(3):993-7. 
39 Yu L, Bennett JT, Wynn J, Carvill GL, Cheung $\mathrm{YH}$, Shen Y, et al.; University of Washington Center for Mendelian Genomics. Whole exome sequencing identifies de novo mutations in GATA6 associated with congenital diaphragmatic hernia. J Med Genet. 2014 Mar;51(3):197-202

40 Qiao Y, Zhang Z, Huang W, Pang S, Xing Q, Yan B. Two functional sequence variants of the GATA6 gene promoter in patients with indirect inguinal hernia. Gene. 2014 Aug; 547(1):86-90.

41 Gaffney J, Solomonov I, Zehorai E, Sagi I. Multilevel regulation of matrix metalloproteinases in tissue homeostasis indicates their molecular specificity in vivo. Matrix Biol. 2015 May-Jul;44-46:191-9.

42 Woessner JF Jr. Matrix metalloproteinases and their inhibitors in connective tissue remodeling. FASEB J. 1991 May;5(8):2145-54.

43 Rosch R, Klinge U, Si Z, Junge K, Klosterhalfen B, Schumpelick V. A role for the collagen I/III and MMP-1/-13 genes in primary inguinal hernia? BMC Med Genet. 2002;3(1):2.

44 Smigielski J, Kołomecki K, Ziemniak P, Drozda R, Amsolik M, Kuzdak K. Degradation of collagen by metalloproteinase 2 in patients with abdominal hernias. Eur Surg Res. 2009; 42(2):118-21.

45 Jain V, Srivastava R, Jha S, Misra S, Rawat NS, Amla DV. Study of matrix metalloproteinase-2 in inguinal hernia. J Clin Med Res. 2009 Dec;1(5):285-9.
46 Smigielski J, Brocki M, Kuzdak K, Kołomecki K. Serum MMP 2 and TIMP 2 in patients with inguinal hernias. Eur J Clin Invest. 2011 Jun; 41(6):584-8.

47 Antoniou GA, Tentes IK, Antoniou SA, Simopoulos C, Lazarides MK. Matrix metalloproteinase imbalance in inguinal hernia formation. J Invest Surg. 2011;24(4):145-50.

48 Zhang Y, Han Q, Fan H, Li W, Xing Q, Yan B. Genetic analysis of the TBX2 gene promoter in indirect inguinal hernia. Hernia. 2014 Aug; 18(4):513-7.

49 Zhao Z, Tian W, Wang L, Wang H, Qin X, Xing $\mathrm{Q}$, et al. Genetic and functional analysis of the TBX3 gene promoter in indirect inguinal hernia. Gene. 2015 Jan;554(1):101-4.

50 Joss S, Kini U, Fisher R, Mundlos S, Prescott K, Newbury-Ecob R, et al. The face of Ulnar Mammary syndrome? Eur J Med Genet. 2011 May-Jun;54(3):301-5.

51 Jorgenson E, Makki N, Shen L, Chen DC, Tian C, Eckalbar WL, et al. A genome-wide association study identifies four novel susceptibility loci underlying inguinal hernia. Nat Commun. 2015 Dec;6(Dec):10130.

52 Mihailov E, Nikopensius T, Reigo A, Nikkolo C, Kals M, Aruaas K, et al. Whole-exome sequencing identifies a potential TTN mutation in a multiplex family with inguinal hernia. Hernia. 2017 Feb;21(1):95-100.

53 Kalluri R, Weinberg RA. The basics of epithelial-mesenchymal transition. J Clin Invest. 2009 Jun;119(6):1420-8.

54 Lee JM, Dedhar S, Kalluri R, Thompson EW. The epithelial-mesenchymal transition: new insights in signaling, development, and disease. J Cell Biol. 2006 Mar;172(7):973-81.
55 Hutson JM, Albano FR, Paxton G, Sugita Y, Connor R, Clarnette TD, et al. In vitro fusion of human inguinal hernia with associated epithelial transformation. Cells Tissues Organs. 2000;166(3):249-58.

56 Colomiere M, Ward AC, Riley C, Trenerry MK, Cameron-Smith D, Findlay J, et al. Cross talk of signals between EGFR and IL-6R through JAK2/STAT3 mediate epithelialmesenchymal transition in ovarian carcinomas. Br J Cancer. 2009 Jan;100(1):134-44.

57 Somuncu S, Somuncu ÖS, Ballica B, Tabandeh B. Deficiency of Epithelial-Mesenchymal Transition Causes Child Indirect Inguinal Hernia. J Pediatr Surg. 2020 Apr;55(4):66571.

58 Kingsnorth A, LeBlanc K. Hernias: inguinal and incisional. Lancet. 2003 Nov;362(9395): 1561-71.

59 Read RC. Inguinal herniation in the adult, defect or disease: a surgeon's odyssey. Hernia. 2004 Dec;8(4):296-9.

60 van Wessem KJ, Simons MP, Plaisier PW, Lange JF. The etiology of indirect inguinal hernias: congenital and/or acquired? Hernia. 2003 Jun;7(2):76-9.

61 Hosgor M, Karaca I, Ozer E, Erdag G, Ulukus $\mathrm{C}$, Fescekoglu $\mathrm{O}$, et al. The role of smooth muscle cell differentiation in the mechanism of obliteration of processus vaginalis. J Pediatr Surg. 2004 Jul;39(7):1018-23.

62 Hutson JM, Kearsey I. Is the ovary in an inguinal hernia 'descended' like a testis or not? J Pediatr Surg. 2016 Jul;51(7):1197-200. 